\title{
Digital Services' Utilization Pattern among Farmers of Central Zone Uttar Pradesh, India
}

\author{
Naveen Kumar Gautam*
}

Chandra Shekhar Azad University, Kanpur-208002 uttar Pradesh, India

*Corresponding author

\section{A B S T R A C T}

Keywords

ATIC, Internet, Digitization

Article Info

Accepted:

15 December 2019

Available Online:

20 January 2020
An exploratory study on internet utilization pattern among farmers is conducted in the central zone of Uttar Pradesh. Examine study, Information sharing and entertainment related factors that may affect the adoption of an innovation or product such as personal computer laptop mobile etc. For the study, a scale was developed by Department of Agricultural extension to measure internet utilization pattern of 225 farmers and farmers were approached personally by the investigator for the collection of relevant data the result of study suggests that most of the respondents have the positive effect on their overall performance due to digital services use.

\section{Introduction}

At present time digitization is a necessity from every point of view. Tracing money, growth, development and evaluation of various schemes are possible because of digitization. Various ideas can spread easily with the help of digital tech, like subsidy schemes of state and central government. A farmer can track new opportunities in agriculture sector with the help of just his mobile, that's the benefit of digitization and in India agriculture is a type of individuals work, which is completely unorganized and digitization is a tool which can organized it.
The main objectives of this study includes, Finding digital services' utilization pattern among farmers of central zone Uttar Pradesh

\section{Materials and Methods}

To measure the Digital services' utilization pattern among farmers, a total of 3 indicators was used viz. 1) Availability of digital/online communication services; 2) Utilization pattern of digital services based on purpose; 3) Medium/device for utilizing digital services; For gathering information from our chosen 225 farmers, a questionnaire was made with the help of extension 
experts and interview method was preferred for it.

\section{Results and Discussion}

The availability of various communication services was observed and presented table. The result reveals that availability of jansevakendra was the highest 90.22 percent among the farmers' respective areas followed by kissan call centre 85.33 percent, IVRI helpline 48.00 percent, sugarcane information centre 38.66 percent, cahupalsagar 49.77 percent, hariyalikissan bazaar 56.44 percent, computer and internet centre 64.55 percent, jansevakendra 90.22 percent and telephone 0.9.77 percent.

Thus, it can be concluded that maximum farmers gather information from jansevakendra and Kissan call centre. Telephone is least usable medium for communication among farmers.

The study of utilization pattern-based purpose shows that 67.22 percent farmers used digital services for communication mostly, 25.33 percent used it often and 3.55 percent used it some time. Second purpose of digital services is information gathering, maximum 57.77 percent farmers used it for this purpose, 25.33 percent used it often and 5.77 percent used it some time. In case of data sharing 49.33 percent, farmers used digital services, 28.44 percent used it often and 15.55 percent used it some time. For banking purpose maximum 46.66 percent farmers used digital services, 27.55 farmers used it often and 09.77 farmers used it sometimes. Entertainment is also a purpose of using digital services, mostly 32.00 percent farmers used it regularly, 15.55 percent used it often and 2.66 percent used it sometimes. For shopping only 20.00 percent used it mostly, follow them 14.22 percent farmers used it often and 08.00 percent used it some time.

Observing above table we can say that maximum 76.44 percent farmers used their own smartphone for using digital services and 17.77 percent farmers used others smartphone. Second device which was commonly used is laptop, 39.55 percent farmers used personal laptop and 52.00 percent used others. Desktop for digital services is very rarely used, only 03.55 percent used personal desktop and 06.66 percent used others.

Table.1 Availability of digital/online communication services

\begin{tabular}{|l|l|c|c|}
\hline S.No. & $\begin{array}{l}\text { Digital/online communication } \\
\text { services }\end{array}$ & Availability & Percentage \\
\hline $\mathbf{1}$ & Kissan call centre (KCC) & 192 & 85.33 \\
\hline $\mathbf{2}$ & IVRI helpline (ATIC) & 108 & 48.00 \\
\hline $\mathbf{3}$ & Sugarcane Information System & 87 & 38.66 \\
\hline $\mathbf{4}$ & Chaupal Sagar (ITC) & 112 & 49.77 \\
\hline $\mathbf{5}$ & HariyaliKissan Bazaar (HKB) & 127 & 56.44 \\
\hline $\mathbf{6}$ & Computer and internet centre (CIC) & 145 & 64.44 \\
\hline $\mathbf{8}$ & Jan sevakendra & 203 & 90.22 \\
\hline $\mathbf{7}$ & Telephone & 22 & 09.77 \\
\hline
\end{tabular}


Table.2 Utilization pattern of digital services based on purpose

\begin{tabular}{|l|l|c|c|c|}
\hline S.No. & Digital services & \multicolumn{3}{|c|}{ Utilization pattern } \\
\hline $\mathbf{1}$ & Banking & 105 & Often & Sometime \\
\hline $\mathbf{2}$ & Shopping & $(46.66)$ & $(27.55)$ & 22 \\
& & 45 & 32 & 18 \\
\hline $\mathbf{3}$ & Information gathering & $(20.00)$ & $(14.22)$ & $(08.00)$ \\
\hline $\mathbf{4}$ & Communication & 130 & 47 & 13 \\
& & $(57.77)$ & $(20.88)$ & $(05.77)$ \\
\hline $\mathbf{5}$ & Entertainment & 152 & 57 & 8 \\
& & $(67.55)$ & $(25.33)$ & $(3.55)$ \\
\hline $\mathbf{6}$ & Data sharing & 72 & 35 & 6 \\
& & $(32.00)$ & $(15.55)$ & $(2.66)$ \\
\hline
\end{tabular}

Table.3 Medium/device for utilizing digital services

\begin{tabular}{|l|l|l|l|}
\hline S.No. & Medium & Personal & Others/cybercafe \\
\hline $\mathbf{1}$ & Smartphone & $172(76.44)$ & $40(17.77)$ \\
\hline $\mathbf{2}$ & Laptop & $89(39.55)$ & $117(52.00)$ \\
\hline $\mathbf{3}$ & Desktop & $08(03.55)$ & $15(06.66)$ \\
\hline
\end{tabular}

Overall observation on this study revealed that utilization pattern of digital services among farmers was categorized into three groups vize. Mostly, often and sometimes. In most category digital services are used through jansevakendra followed by kissan call centre, sugarcane information system, hariyalikissan bazar, cybercafé respectively for communication and information.

In other category, primary purpose of digital services utilization is communication then information gathering followed by banking, data sharing, entertainment and shopping respectively. In category of devices which were used as medium for digital services smartphone came first followed by laptop and desktop respectively.

On the basis of our study we can conclude that our most of farmers are familiar with the smartphone and its use and if digital technology is highly used for communication, it happens only because of smartphones. Currently internet is easily available in rural areas also that's why now jansewakendras are most popular among farmers and these jansewakendras helping farmers in various ways like providing information about gov. scheme and applying for it, generating various documents etc. Computers and laptops became essential now these days, direct use of them by farmers can be very little but effect of these in their life is huge. After communication these digital services are used for information gathering and data sharing mostly except shopping and we can very few farmers believed in online shopping. But use and users of digital services are really growing and in field of agriculture it happening very fast. 


\section{References}

Kadian, K. S. Internet utilization pattern among students of a national institute an exploratory study. Diss. NDRI, Karnal, 2017.

Kalbande, D. T., and Shashank S. Sonwane. "Use of Consortium for e-Resources in Agriculture (CeRA): A Case Study." International Journal of Library and Information Studies 2.1 (2012): 33-41.

Lakan, E. Lydia. "Availability and Utilization of Electronic Information Databases by Staff of the Agricultural Complex, Ahmadu Bello University, Zaria." Samaru Journal of Information Studies 8.1 (2008): 44-53.

Lalotra, Seema, and Sangita Gupta. "Information Needs and Expectations in Digital Era: A Study of Select Agricultural Institutes in Northern India." Trends in Information Management 6.2 (2010).

\section{How to cite this article:}

Naveen Kumar Gautam. 2020. Digital Services' Utilization Pattern among Farmers of Central Zone Uttar Pradesh, India. Int.J.Curr.Microbiol.App.Sci. 9(01): 707-710. doi: https://doi.org/10.20546/ijcmas.2020.901.076 